\title{
A Study on the Accident Reasonidentification and Reinforcement of the Floated Basement
}

\author{
Yu Zhang \\ Guizhou Hongxin Chuangda Engineering Detection \& Consultation Co. Ltd. \\ No.949 Gao-hai road of Guiyang \\ 273652902@qq.com
}

\begin{abstract}
Underground structure cracking and damage caused by anti - float underground space project, which is a hot and difficult problem in the engineering of recent years. This paper is aimed the accident of the floated basement floor, column, beam, and wall cracking due to the precipitation, at the basement floor of a building in Sichuan. The field detection and identification are carried out. The cause of the floated basement floor and the mechanism of structural damage are clarified. Based on this, the permanent anti floating treatment and structure strengthening treatment of the basement structures are carried out, which achieved good economic and social benefits. And the research work has certain guiding significance to the basement floating problem.
\end{abstract}

Key words-Basement; anti - floating; damage detection; accident identification; reinforcement

\section{I . INTRODUCTION}

In recent years, with the fast development of China's city construction, more and more urban population, the more limited space available on the ground, and the development and utilization of underground space has become an inevitable trend. Thus, Large numbers of high-rise buildings, underground shopping malls, underground garage and other underground structures with basement.

With the development and utilization of underground space, the depth of the underground concrete structure and the volume of the underground concrete structure increase rapidly. After the completion of the construction of the basement, due to the under the influence of the surrounding precipitation, concrete basement floor very easy to produce floating deformation, also have different degrees of cracks, the basement structure of columns, beams and other structural also prone to larger cracks. Which seriously affected the underground structure of the normal use and safety, often requires the use of loading and the bottom unloading pressure method to make the structural stability of the floating and as far as possible to restore the original state, at the same time, we should reinforce the damaged component[1-4]. Due to the lack of a systematic study of the basement anti floating problem, coupled with anti floating design and site construction still exist some defects, resulting in some underground space engineering because of the anti floating problems caused by cracking or even the destruction of the underground structures, and seriously affect the duration, resulting in huge economic losses[1, 2].

This paper, in Sichuan, a construction of the basement floor and basement structure beam, column, due to the floor floating resulted in inhomogeneous deformation and cracking of the structure of accident, to carry out field detection of structural damage, clarify the accident of floating and damage mechanism, and based on this, the basement structure engineering of permanent anti floating treatment as well as structure strengthening method research.

\section{II . A GENERAL SITUATION OF ENGINEERING}

A construction project in Sichuan, the main building for the ground floor of the residential building 18 28, the use of frame and shear wall structure, based on the use of pile foundation. The basement storey is mainly $3.90 \mathrm{M}$, the total construction area of the basement is $7993.59 \mathrm{~m}^{2}$, the foundation of the independent column or strip foundation under wall, to completely weathered mudstone layer or clay layer for bearing stratum, foundation bearing force characteristic of FAK is greater than or equal to $180 \mathrm{kpa}$ value. 
The basement waterproof floor thickness is $300 \mathrm{~mm}$, and

the steel bar for a double-way is C12@150.In early 10 after the rain of 2014, the project of the basement section of the beam column has cracking phenomenon, the part of the wall to fill the cracks, the basement floor of the arch deformation up to $17 \mathrm{~cm}$.After investigating the scene of the accident, it was found that the basement floor and some reinforced concrete columns, beams, walls and other structures have different degrees of damage.

1) In the basement of the engineering part of the floor cracks, there is a clear water seepage phenomenon, see Fig. 1. After the bottom hole pressure relief, there is still a small amount of groundwater gush, as shown in Fig.2;

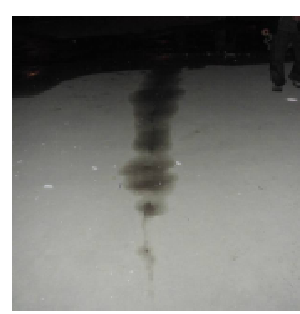

Fig. 1 Cracked floor with seepage



Fig. 3 Concrete breaker at the column foot



Fig.2 Drilling relief onbackplane

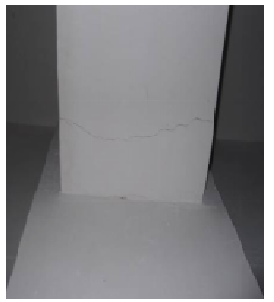

Fig. 4 Bending cracks at beam end Section
2) At the beginning individual reinforced concrete column column in the lower part of the local concrete crisp broken, see Fig. 3; Due to the portion of the adjacent column vertical relative displacement caused by buoyancy, resulting in connection to reinforced concrete beam column in the area near support appeared typical flexural cracks, as shown in Fig. 4.;

3)The typical oblique shear cracks appear in the partially filled wall, as shown in Fig. 5.

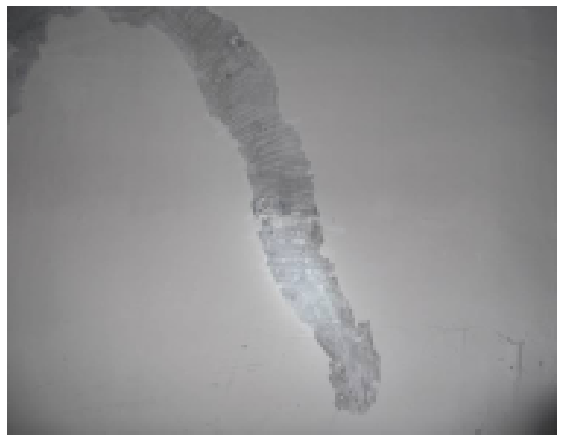

Fig. 5 Diagonal shear crack of the filler wall

\section{ANALYSIS OF THE CAUSE OF THE ACCIDENT}

According to the field test and appraisal analysis, the concrete strength, section size and reinforcement configuration of the frame column and beam in the damaged area are all satisfied with the design requirements. According to the geotechnical engineering survey and data analysis, types of groundwater in soil of perched water and bedrock fissure water, no uniform stability of underground water level. Construction after excavation to form a depth 3.0 12.0m, covers an area of deep foundation pit area of about $30000.0 \mathrm{~m} 2$. Ting mudstone clay layer, or layer, foundation pit surrounding existing different layer thick, strong weathered mudstone layer, layer of clay, the clay with micro expansion and fracture is developed.

2014 in September and October produced abundant rainfall, rainwater through the fertilizer tank loose fill and make foundation pit low-lying catchment area; Due to the basement flohe foundation pit soil mainly complete strong weather

or and retaining wall to form a closed bowl structure and the surrounding catchment will form the high pressure head, which on the basement floor produced larger floating pressure, coupled with the anti water board is thin (300 mm), resulting in the local region or floating arch deformation, and thus lead to beam, column and wall crack of basement structure. The basement structure beams, columns, wall crack has been on the structural safety and durability caused some adverse effects, component has emerged of the bearing force of fracture and damage, so it is urgent to conduct study on method of strengthening.

\section{IV . Reinforcement of the floated basement}

\section{A. Reinforcement content}

According to the actual situation, to carry out the following reinforcement:(1) due to excavation caused by 
rainfall catchment water sinks against the plate produced a greater pressure on the floating, drilling pressure relief;(2) due to the local area of floating or arch deformation, resulting in structural beam and column cracking, need to carry out the reinforcement and repair of load-bearing structure;(3) the cracking and damage of water plate caused by the local floating in the basement should be repaired and treated.

\section{B. Reinforcement scheme}

According to the detection and identification of the floating accident in the basement, based on the analysis of the cause of the accident, according to the project put forward the following treatment:(1)The transformation of the existing sump, diversion pipeline to divert due to atmospheric precipitation (surface water) produced by groundwater; (2)The cracks in the basement floor and roof are closed and repaired, and the carbon fiber cloth is used to reinforce the cracks; (3)Repair of concrete column structure with local displacement method; (4)Combined with the method of outsourcing steel and the local replacement of joints, the damage of concrete column is repaired;(5)Through the carbon fiber, repair the cracks in the beam structure damage.

\section{Anti floating treatment of basement}

According to the basement anti floating design method, at present, the following 3 methods are mainly used [4-6].(1) the weight of anti floating methods include substrate loading, roof ballast and side wall loading;(2) Anti floating anchor: including uplift pile anti floating and anti floating anchor. The former is the uplift pile side friction and the pile overcome the heavy buoyancy, the latter as in the bottom plate and the lower layer between the draw rod is arranged;(3)Borehole pressure relief.According to the actual situation and the surrounding environment of the project, this paper mainly uses the method of precipitation pressure relief to carry out anti floating treatment.

Due to the basement floating, have been carried out by drilling the bottom diameter $10 \mathrm{cmdrainage}$ treatment, holes are arranged on the bottom plate arch deformation zone is larger and of water gushing were effectively drainage.Needle against water damage, this paper first to crack the site open $U$ slot, and then the use of plugging agent on the crack plugging processing, and then paste carbon fiber reinforced concrete approach to the specific practice see Fig. 6.In view of the existing sump. In this paper, the increased diversion pipeline way to divert due to atmospheric precipitation, surface water, groundwater, and use the discharge pressure of underground water head pressure reduction, to ensure that the anti floating stability of basement structure and specific practices see Fig. 7.

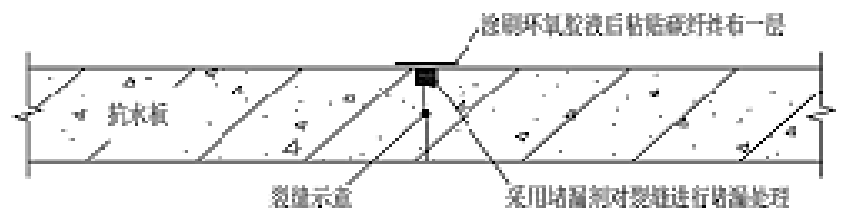

Fig. 6 Damage repair of water-resistant board

According to Fig. 6 shows, the first anti water board will need to get rid of eliminate concrete and then apply as filter layer, and then into and fixed 321 stainless steel tube diameter 133 delta 4, and restore the cushion and waterproof construction, and will be reinforced according to the original structural restoration, finally re pouring the mixed expansion agent and anti crack fiber compensation shrinkage waterproof concrete.

The relief well construction method: first of all to get rid of the concrete next to the water collection well, followed by the different size of gravel and gravel composed of anti filter layer; once again to install diversion pipe; Finally closed processing. After the field test, the diversion pipeline can be successfully imported into the water collecting well, and finally, through concentrated and continuous drainage, in order to achieve the purpose of precipitation.

In this paper, the anti floating treatment measures are used to achieve the effect of the water pressure relief, the basic solution to the basement floor of the local floating problem, and achieved good engineering benefits.

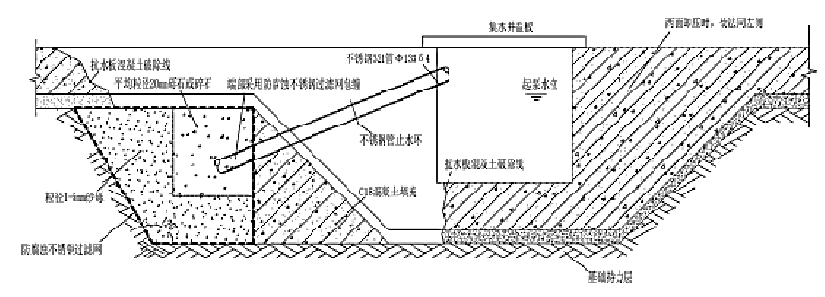

Fig.7 Schematic of sump transformed into relief well

\section{Strengthening treatment of basement structure}

Because of the basement floating, basement beams, columns, walls and slabs, members have different forms and degrees of damage. Therefore, it is necessary to take comprehensive reinforcement treatment methods and measures, the reinforcement of the damaged member. The 
reinforcement treatment method used in this paper mainly has the following $4[7-10]$.

1) In view of the damage of reinforced concrete columns, combined with the outsourcing of steel and the method of node partial replacement, and other methods to repair. First, cut in addition to the original cracking and crushing of concrete, revealing a solid grass-roots, the surface pores and uneven place that should be adopted in the epoxy mortar moping; secondly, the steel plate bonding surface and surface polishing of roughening treatment. Finally, the plate is placed predetermined position with adhesive in plastic injection pressure, as shown in Fig. 8.

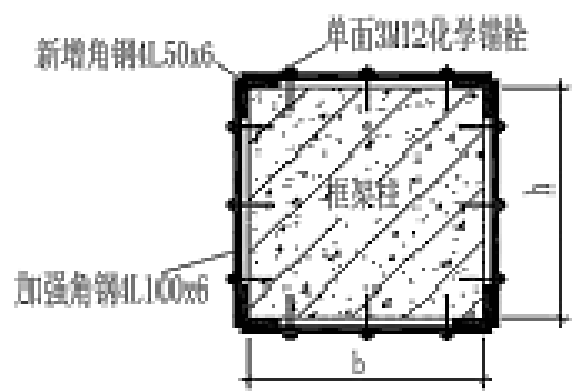

Fig.8 Reinforcement schematic of concrete column

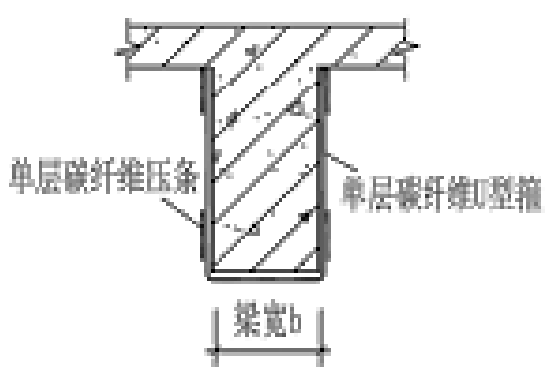

Fig.9 Reinforcement schematic of the main beam of basement

2) In order to produce cracks in the main beam, the use of carbon fiber method to repair the paste (Fig. 9):First, the beam surface polished smooth and depression by leveling glue to repair, and the acetone wipe coated with a primer layer, corner paste of chamfer and polished into a circular arc shape. Secondly, the adhesive evenly wipe the paste position of the concrete surface, laying carbon fiber cloth; subsequently, the roller along the fiber direction repeatedly rolling, so that it is flat and without bubble; then, according to the carbon fiber sheet strengthening technical specification for concrete structures[11] pasting carbon fiber cloth, cement mortar. Finally, the effect of carbon fiber reinforcement is tested.
3) The basement roof crack can be treated with reference to the water board treatment method.

4) Aiming at the cracks in the basement wall, combined with the planting and pasting carbon fiber cloth, repair treatment (Fig. 10):First by using polyurethane foam plugging cracks in the wall, then clean out concrete chisel except line; then implanted steel and new reinforced mutual welding; followed by the use of cement based grouting material for pouring; Finally in the surface layer is pasted a layer of carbon fiber cloth.

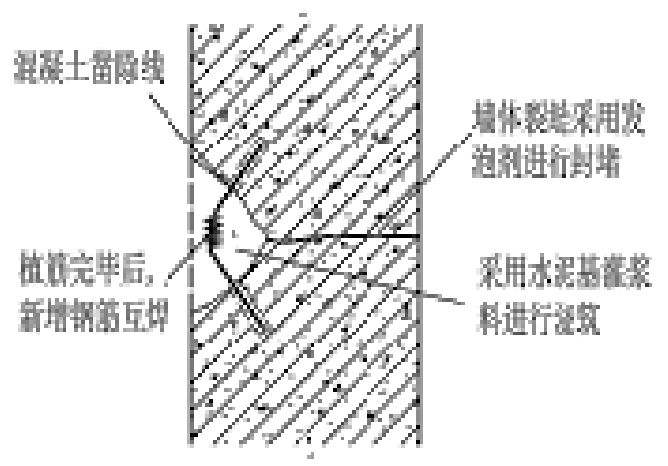

Fig. 10 Reinforcement schematic of basement walls

\section{CONCLUSION}

This article is aimed at the basement of a building in Sichuan, due to the local surface deformation and cracking of the basement floor caused by rainfall, some structural beams and columns, as well as the cracking accident of the wall, through the field detection of damaged structures, the causes of the accident and the mechanism of structural failure were found out, and based on this, the research on the permanent anti floating treatment of the basement structure and the method of structural strengthening treatment are carried out. In the following several heavy rain, the structure of the basement did not find the abnormal phenomenon and the phenomenon of water seepage, which showed that the reinforcement treatment effect is good, the basement has met the requirements of the permanent anti floating and safe use, and has achieved good economic and social benefits. The research work in this paper has some guiding significance to the floating of the basement.

\section{REFERENCES}

[1] ZHANG Yiwei, ZHANG Ruixing,"REMEDY OF FLOATING UP/CRACKS OF LARGE REINFORCED CONCRETE POND”, Architecture Technolgy,vol. 4, pp. 279-280, April 2003.

[2] Liu Wenjing, Yang Jianzhong, Wang Ni, “TEST APPRAISAL AND REINFORCEMENT OF A FLOATED BASEMENT”, Industrial buildings,vol. 40, pp. 127-130, May2010. 
[3] Yan Dawei, Zhao Xuming, Shen Jinxin, "Identification and reinforcement of a factory in Lanzhou City, second water plant", Building Science Research of Sichuan, vol. 33, pp.178-180, Sep.2007.

[4] XU Chunguo, "Identification and reinforcement of the floating cracking accidents in the basement”, Building Structure, vol. 32, pp. 26-28, Nov.2002.

[5] JIA Jinging, CHEN Jinjie, "DESIGN AND CONSTRUCTION TECHNOLOGY FOR ANTI-FLOATING WORKS OF LARGE UNDERSTRUCTURE”, Architecture Technology, vol. 33, pp. 352-353, May2002.

[6] “Code for load of building structures”. (GB 50009—2001)

[7] “Code for design of concrete structures”.(GB 50367—2006)

[8] "Technical specifications for the reinforcement of existing building foundation". (JGJ 123-2000)

[9] WANG Sixin, QU Na, "DEALING WITH THE PRoBLEM OF SLOPING BUILDING BASEMENT'SANTI-UPLIFT WITH GREEN TECHNoLoGICAL METHoDS”, vol. 43, pp. 925-928, Sep.2012.

[10] GUO Huizhen, "Design scheme and construction of reinforced concrete frame structure for underground adding layer”, vol. 11, pp.56-60,June2014.

[11] "Technical specification for concrete structures strengthened with carbon fiber sheets”,(CECS 146-2003) 